This article has been published in Acta Materialia. The final publication is available at

Elsevier via https://doi.org/10.1016/j.actamat.2018.06.026

\title{
Synchrotron tomographic quantification of the influence of Zn concentration on dendritic growth in Mg-Zn alloys
}

\author{
Sansan Shuai ${ }^{a}$, Enyu Guo ${ }^{\mathrm{b}}$, Jiang Wang ${ }^{\mathrm{a}}$, A.B. Phillion ${ }^{\mathrm{d}}$, Tao Jing ${ }^{\mathrm{c}}$, Zhongming \\ Ren $^{a}$, and Peter D Lee ${ }^{e, f}$ \\ a School of Materials Science and Engineering, Shanghai University, China \\ ${ }^{\mathrm{b}}$ Key Laboratory of Solidification Control and Digital Preparation \\ Technology (Liaoning Province), School of Materials Science and Engineering, \\ Dalian University of Technology, China \\ ${ }^{\mathrm{c}}$ School of Materials Science and Engineering, Tsinghua University, China \\ ${ }^{\mathrm{d}}$ Department of Materials Science and Engineering, McMaster University, Canada \\ ${ }^{\mathrm{e}}$ Mechanical Engineering, University College London, UK \\ ${ }^{\mathrm{f}}$ Research Complex at Harwell, RAL, Didcot, UK
}

\begin{abstract}
Dendritic microstructural evolution during the solidification of $\mathrm{Mg}-\mathrm{Zn}$ alloys was investigated as a function of $\mathrm{Zn}$ concentration using in situ synchrotron X-ray tomography. We reveal that increasing $\mathrm{Zn}$ content from $25 \mathrm{wt} . \%$ to $50 \mathrm{wt} . \%$ causes a Dendrite Orientation Transition (DOT) from a six-fold snow-flake structure to a hyperbranched morphology and then back to a six-fold structure. This transition was attributed to changes in the anisotropy of the solid-liquid interfacial energy caused by the increase in $\mathrm{Zn}$ concentration. Further, doublon, triplon and quadruplon tip splitting mechanisms were shown to be active in the Mg-38wt.\%Zn alloy, creating a hyperbranched structure. Using the synchrotron tomography datasets, we quantify, for the first time, the evolution of grain structures during the solidification of these alloys, including dendrite tip velocity in the mushy zone, solid fraction, and specific surface area. The results are also compared to existing models. The results demonstrate the complexity in dendritic pattern formation in hcp systems, providing critical input data for the microstructural models used for integrated computational materials engineering of Mg alloys.
\end{abstract}

Keywords: magnesium alloys; zinc; 4D imaging; dendrite orientation transition; morphology transition. 


\section{Introduction}

As the lightest structural metal widely used for automotive and aerospace applications, Mg alloys have tremendous opportunity for lightweighting vehicles and improving fuel efficiency[1][2][3]. Due to their excellent fluidity[2], most components made from $\mathrm{Mg}$ are generally cast into a near-net-shape mould. At the scale of the microstructure, the casting process refers to the formation of dendrites, eutectic, and precipitate constituents as the metal evolves from the liquid to the solid state[4][5][6]. The morphology and size distribution of these features significantly affects other phenomena - micro-segregation, intermetallic precipitation, semisolid rheology, and grain texture - and thus determines the in-service mechanical properties[7].

The formation of dendrites during solidification is largely controlled by the underlying crystalline structure, diffusion (both heat and solute), and anisotropy in the solid/liquid interfacial energy[4][8]. In metallic systems, a variety of dendritic morphologies and growth patterns have been observed, from the expected cubic/hexagonal morphology to feathery and seaweed grains, hyperbranched structures, and dendrite orientation transitions. These observations were made post-mortem, historically in 2D (via metallography, scanning electron microscopy[9][10][11]) and more recently in 3D (via serial sectioning and X-ray tomography[12][13][14]), on samples quenched from the semi-solid regime to "freeze-in" the microstructure. In a comprehensive study on $\mathrm{Mg}$ alloys, Yang et al.[15] performed post-mortem X-ray tomography to examine the effect of solute content on dendrite morphology and orientation selection using $\mathrm{Sn}, \mathrm{Ba}, \mathrm{Al}, \mathrm{Y}, \mathrm{Gd}$, and $\mathrm{Zn}$ elements. In particular, for $\mathrm{Mg}$ - 
$\mathrm{Zn}$, a dendrite orientation transition was observed in which seaweed-like $\alpha-\mathrm{Mg}$ structures grew for $\mathrm{Zn}$ content between 20-45 wt.\%, while 18-branch $(<20 \mathrm{wt} . \% \mathrm{Zn})$ and 12-branch ( $>45 \mathrm{wt} . \% \mathrm{Zn})$ morphologies were observed outside this range. In a similar post-mortem X-ray tomography study, Shuai et al.[11] also observed a dendrite orientation transition, however the seaweed structure was not seen until $38 \mathrm{wt} . \% \mathrm{Zn}$. These studies showed the possibility to control the dendritic formation patterns of $\mathrm{Mg}$ alloys through alloy additions.

Recently, due to advances in high-speed synchrotron X-ray radiography and tomography, in situ studies of microstructure evolution during the processing of metallic materials have been reported[16][17][18][19][20][21][22][23]. Real-time radiographic experiments at ultrafast frame rates have been largely carried out on Albased alloys (Al-Cu[24][25][26], Al-Ni[27], Al-Si[28][29]) with thin plate-like (100$200 \mu \mathrm{m})$ samples, in order to study solidification phenomena including dendrite coarsening, columnar-to-equiaxed transition, crystal fragmentation [26], and crystallographic misorientation [30]. In situ tomographic experiments, known as 4D imaging, have also been performed on similar cubic alloy systems (but at a much slower frame rate) to elucidate the corresponding $3 \mathrm{D}$ evolution in solidification microstructure[9][31][32][33][34]. For the case of Mg, with hcp crystallography and high affinity for oxygen, direct 2D and 3D observations of dendritic morphology evolution during solidification are limited[19][35][36]. Using radiography, Wang et al.[19] investigated the effect of cooling rate on dendritic growth dynamics of $\mathrm{Mg}-\mathrm{Gd}$ alloy in a fixed thermal gradient. Using tomography, Shuai et al.[35] quantified the 
effect of the cooling rate on 3D dendritic morphology evolution in a Mg-Sn alloy while Guo et al.[37] examined the influence of cooling rate and solute concentration on the coarsening kinetics of Mg-Zn alloys.

Collectively, these studies have greatly advanced our understanding of solidification microstructure evolution in complex hcp structures. In addition, they demonstrate the need for further research to reveal the dynamics of microstructural evolution and the underlying mechanisms by which solute elements alter the dendritic structures of hcp Mg alloys.

In the present study, the effect of $\mathrm{Zn}$ content on $\alpha$-Mg dendritic growth patterns was investigated using 4D synchrotron X-ray tomography, X-ray diffraction (XRD) and electron back-scatterred diffraction (EBSD). This research goes beyond the postmortem tomography studies of Yang et al.[15] and Shuai et al.[11] to quantify in situ the evolution in solid fraction $\left(f_{\mathrm{s}}\right)$, dendrite tip velocity in the mushy zone $\left(V_{\text {tip }}\right)$, and specific surface area $\left(S_{\mathrm{v}}\right)$ in alloys having 25 to $50 \mathrm{wt} . \% \mathrm{Zn}$, and qualitatively capture the influence of $\mathrm{Zn}$ on dendrite growth kinetics in hcp Mg alloys. By providing the first quantitative kinetic data, the results both inform and validate numerical solidification models of hcp metals.

\section{Materials and experimental methods}

Three hypoeutectic Mg-Zn alloys with 25, 38 and 50\% weight percent of $\mathrm{Zn}$ were selected for this study, to determine zinc's influence on the dendritic structure. The solidification ranges of the three alloys are $\sim 209^{\circ} \mathrm{C}\left(550-341^{\circ} \mathrm{C}\right), \sim 134^{\circ} \mathrm{C}\left(475-341^{\circ} \mathrm{C}\right)$ 
and $\sim 59^{\circ} \mathrm{C}\left(400 \sim 341^{\circ} \mathrm{C}\right)$, respectively. The methodology for sample preparation and encapsulation enabling 4D imaging of Mg alloy solidification is the same as that in ref.[35]. Note that these are nominal alloy compositions, as evaporative loss may have resulted in a reduction in the $\mathrm{Zn}$ content.

The X-ray tomography experiment was carried out at the Diamond-Manchester Beamline (I13), Diamond Light Source (DLS, UK). Each sample was heated to $30{ }^{\circ} \mathrm{C}$ above the liquidus temperature, held for 30 min to ensure complete melting, and then cooled at a rate of $3^{\circ} \mathrm{C} / \mathrm{min}$. During cooling, tomographic images were acquired continuously until solidification was complete. The acquisition time was $14 \mathrm{~s}$ per tomogram at a voxel size of $1.6 \mu \mathrm{m}$ followed by a $22 \mathrm{~s}$ delay for system re-initialization, giving a cycle time of $36 \mathrm{~s}$. Subsequently, each set of 3D datasets was processed using the Avizo software (ThermoFisher FEI) to visualize the process of solidification in Mg$\mathrm{Zn}$ alloys and segment the solid and liquid phases. The experimental set-up, beam parameters and image processing procedures are the same as those utilized previously[35]. Please note that it was assumed that the melt temperature reached the liquidus temperature in the tomogram prior to the one where the dendrites were first observed irrespective of the thermocouple readout value. Further, based on the cycle time and cooling rate, the temperature difference between each subsequent tomogram was $1.8^{\circ} \mathrm{C}$ and thus this value was also assumed to be the uncertainty in temperature. The XRD and EBSD specimens were prepared by heating cylindrical Mg-Zn alloys to $\sim 30^{\circ} \mathrm{C}$ above the melting point, cooled down at the same rate as the $\mathrm{X}$-ray tomography experiments to $30^{\circ} \mathrm{C}$ below the liquidus, and then quenched into liquid metal coolant 
122

(Ga-In-Sn). The XRD was conducted on a Bruker AXS-D8 Advance system $\left(10^{\circ}\right.$ to $90^{\circ}$, $3 \% \mathrm{~min}$ ). For EBSD, metallography was then performed on a Struers automated grinding and polish machine following the standard procedure. After final polish with OP-S $(0.04 \mu \mathrm{m})$, the specimens were etched for $2-3 \mathrm{~s}$ with a solution of $5 \mathrm{ml}$ nitric acid, $15 \mathrm{ml}$ acetic acid, $20 \mathrm{ml}$ distilled water and $60 \mathrm{ml}$ ethanol. The EBSD was conducted using a Zeiss Crossbeam 540 equipped with NordlysMax2 detector and HKL Channel 5 data analysis system.

\section{Results and discussion}

\subsection{Qualitative analysis}

\subsubsection{Dendritic morphology evolution during solidification}

Fig. 1 and supplementary videos V1, V2 and V3 show the dendritic morphology evolution of three different $\mathrm{Mg}-\mathrm{Zn}$ alloys at different temperatures within the mushy zone as $2 \mathrm{D}$ cross-sectional slices extracted from the middle of each tomogram. As can be seen, distinctive dendritic morphologies were observed at each of the different $\mathrm{Zn}$ contents. Specifically, a coarse and globular-like dendritic structure was obtained at Mg-25wt.\%Zn, a hyper-branched structure was obtained at Mg-38wt.\%Zn, and a dendritic structure with branched arms around the trunk was obtained at Mg-50wt.\%Zn.

For all the alloys, it appears that the majority of the grains nucleated on the sample wall and grew towards the sample center. This is potentially due to the $\mathrm{MgO}$ skin on the surface acting as heterogeneous nucleation sites for the $\alpha-\mathrm{Mg}$ grains[38][39]. With increased solid fraction, an increase in the image contrast was observed. This was a 

the images b4 (Mg-38wt.\%Zn) and c4 (Mg-50wt.\%Zn), increased attenuation in the interdendritic region was observed, suggesting that this region has solidified forming eutectic (i.e. the eutectic temperature was reached), showing as darker in the image due to the solid's increased density and additional scattering of x-rays[25]. This final feature is best seen in supplementary videos V1, V2 and V3. Note that the final $\Delta T$ in Fig. 1 $(\mathrm{a} 4, \mathrm{~b} 4, \mathrm{c} 4)$ does not correspond perfectly to the solidification range for the three alloys from the phase diagram, but instead is $\sim 15^{\circ} \mathrm{C}$ less. This may be due to either evaporative loss of $\mathrm{Zn}$ changing the composition during multiple melting/solidification experiments, and/or a change in the furnace temperature distribution resulting from latent heat evolution. This inaccuracy in the solidification range does not affect the dendritic growth observations, but may shift the $\mathrm{Zn}$ concentration at which they occur.
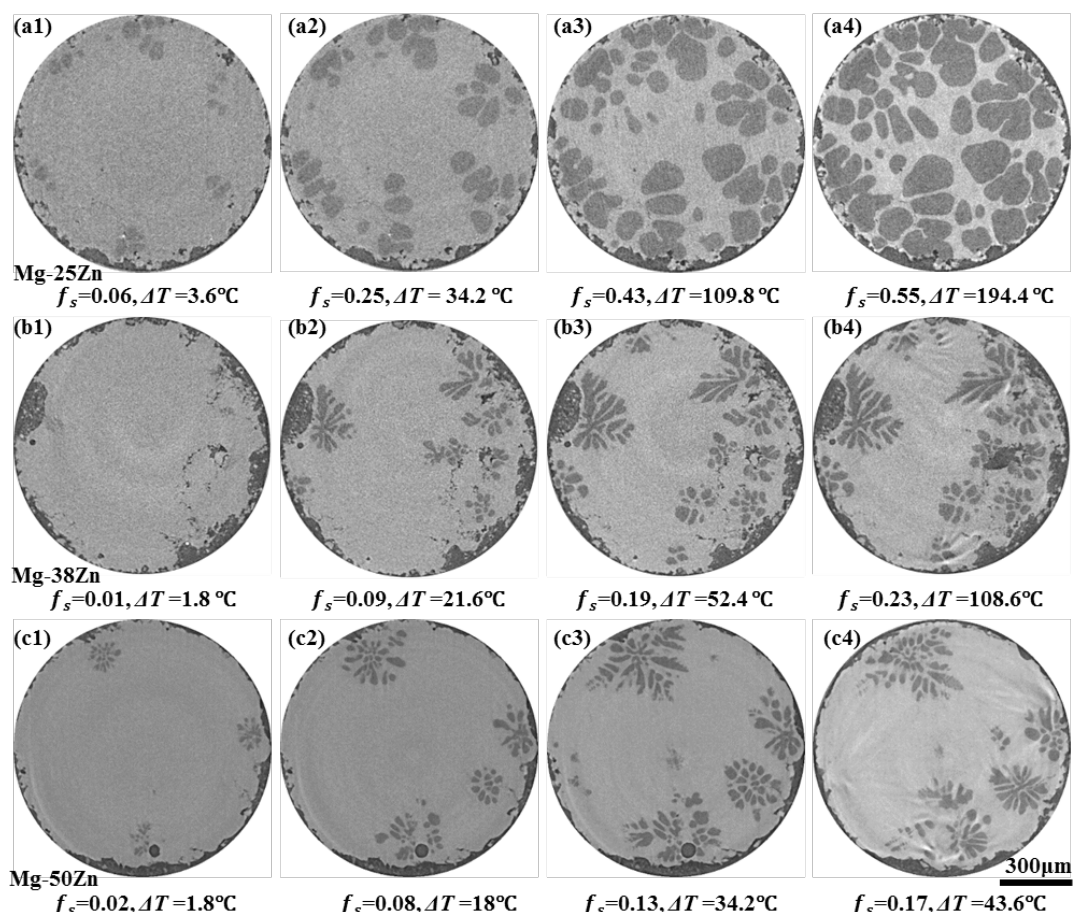

$f_{s}=0.09, \Delta T=21.6^{\circ} \mathrm{C}$

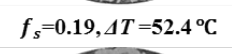

$f_{s}=0.23, \Delta T=108.6^{\circ} \mathrm{C}$
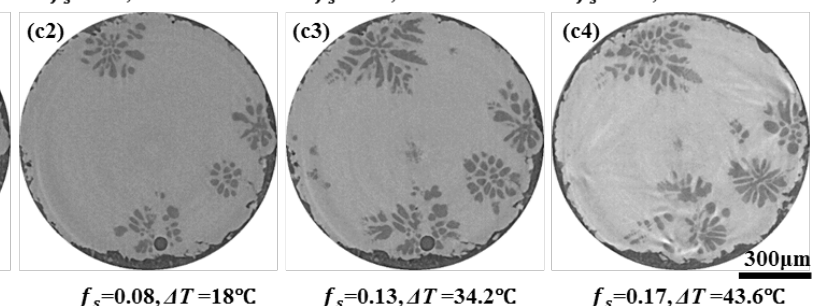

Fig. 1: 2D image sequence showing dendritic morphology evolution as a function of solid fraction and temperature in Mg-25wt.\%Zn (a1-a4), Mg-38wt.\%Zn (b1-b4) and 
Mg-50wt.\%Zn (c1-c4) alloys ( $\Delta T$ indicates the temperature below $\left.T_{\text {liquidus }}\right)$. All the figures share the same scale bar; the dark grey areas on the margin represent the gap between the sample and graphite tube.
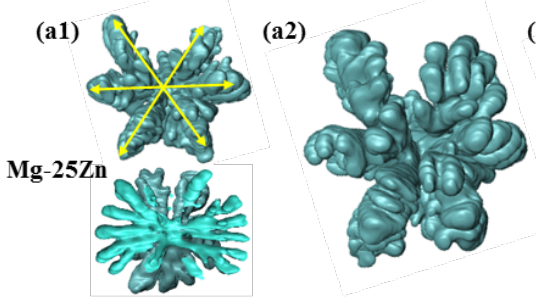

(a3)
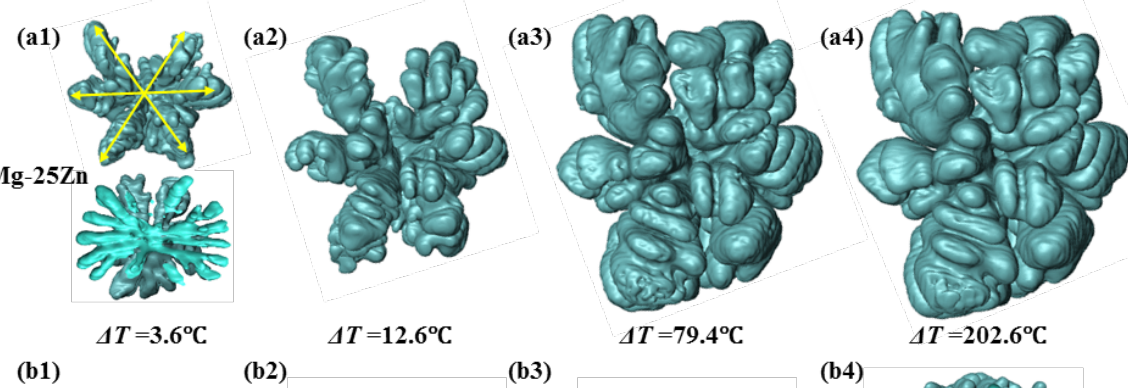

(b2)
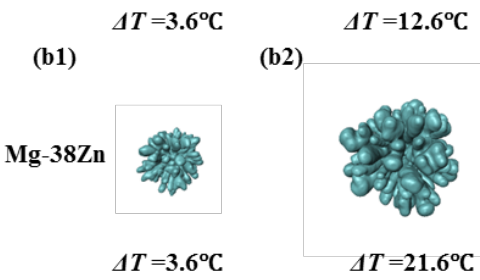

(b3)

$\Delta T=79.4^{\circ} \mathrm{C}$
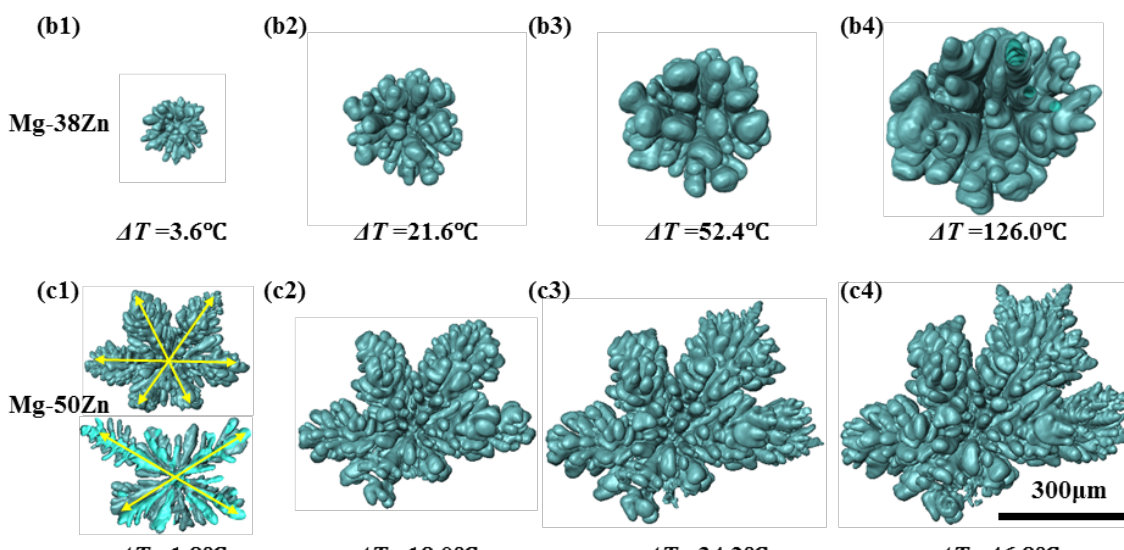

(c2)

(c3)
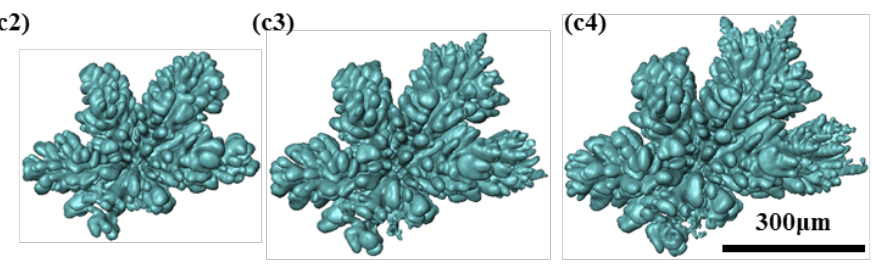

$\Delta T=18.0^{\circ} \mathrm{C}$

$\Delta T=34.2^{\circ} \mathrm{C}$

$\Delta T=46.8^{\circ} \mathrm{C}$

Fig. 2: 3D dendritic morphology evolution for Mg-25wt.\%Zn (a1-a4), Mg-38wt.\%Zn (b1-b4) and $\mathrm{Mg}-50 \mathrm{wt} . \% \mathrm{Zn}$ (c1-c4) alloys ( $\Delta T$ indicates temperature below $T_{\text {liquidus; }}$ all the figures share the same scale bar).

To examine the 3D growth of dendrites during solidification, isolated representative dendrites were extracted from each acquired tomogram. Fig. 2 and supplementary videos V4, V5 and V6 show the morphological evolution of the three $\mathrm{Mg}-\mathrm{Zn}$ alloys tested. From the earliest growth stage onwards, the microstructures of all three alloys are seen to be dendritic from a 3D perspective[35]. For the case of $\mathrm{Mg}$ 25wt.\%Zn, Fig. 2 (a1-a4), it would appear that dendritic growth and coarsening occurred concurrently. For the cases of Mg-38wt.\%Zn and Mg-50wt.\%Zn, dendritic growth is evident but coarsening is more difficult to clearly observe. As coarsening is a time-dependent process, the decreasing solidification interval occurring with increasing $\mathrm{Zn}$ content results in shorter time for the structure to coarsen and thus its effects are 
175 difficult to quantify. It can also be seen from Fig. 2 that, with an increasing Zn content, 176 the morphology of primary $\alpha-\mathrm{Mg}$ grains became more complex with a higher number 177 of dendritic branches, and an increase in the number of secondary dendrite arms. In 178 other words, as the $\mathrm{Zn}$ concentration increases, dendrites in Mg-Zn alloys appear to 179 produce finer branches that split more frequently. This is best seen by comparing Figs. $1802 \mathrm{a} 1, \mathrm{~b} 1$, and $\mathrm{c} 1$.

Fig. 3 plots the local mean curvature distribution for each of the three dendrites

182 shown in Fig. 2 at a time when the average solid fraction in the tomogram was 0.15 . 183 Mean curvature, $H$, is defined as $\left(1 / R_{1}+1 / R_{2}\right) / 2$, where $1 / R_{1}$ and $1 / R_{2}$ are the 184 two principal curvatures at any point on the dendrite. Along with the distribution, 185 images of the three dendrites are shown. In these images, a red colour indicates large 186 positive values of $H$, and thus local regions with large positive mean curvature / 187 dendrite arms having the finest tip radii, while a green colour indicates neutral values 188 of $H$. As can be seen, with increasing $\mathrm{Zn}$ concentration, the dendritic surface area having 189 a large mean curvature also increases. This experimental result agrees well with the 190 experimental finding in succinonitrile-acetone alloys where an increase in dendrite tip 191 curvature was observed with an increase in acetone concentration [40]. 


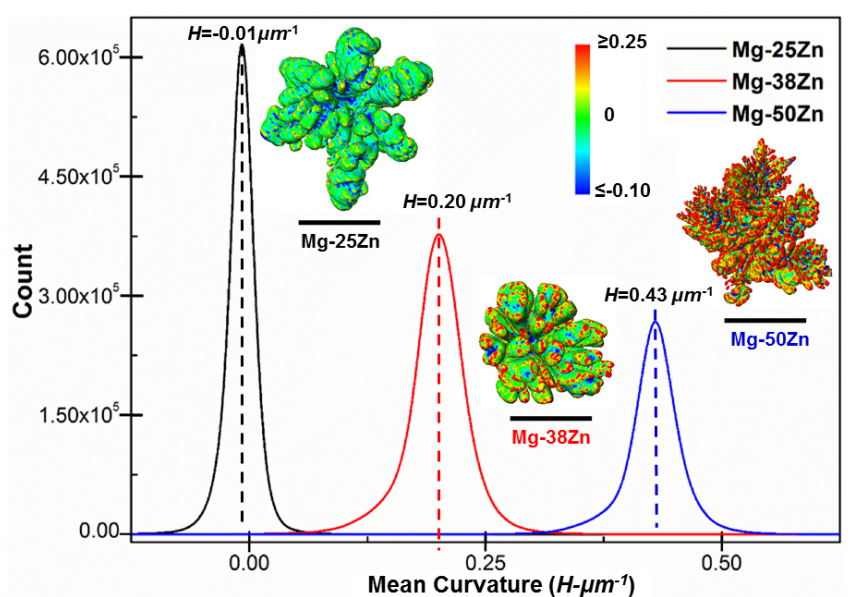

Fig. 3: Mean curvature $(H)$ distribution of separated dendrites in $\mathrm{Mg}-25 / 38 / 50 \mathrm{wt} . \% \mathrm{Zn}$ alloys at a solid fraction of 0.15 . The scale bar has a length of $300 \mu \mathrm{m}$.

\subsubsection{Dendritic morphology transition with increasing Zn concentration}

Dendrites in Mg alloys generally evolve as a six-fold hep symmetric snowflakelike structure[10][41][42][43]. However, due to the weak anisotropy between symmetric growth directions, the preferential growth orientations of $\alpha$-Mg dendrite are influenced by many factors. These include alloying elements and solute concentrations, as well as imposed thermal conditions, resulting in a diversity of $\alpha-\mathrm{Mg}$ dendrite morphologies possessing both six-fold symmetrical structures and those with abnormal structures formed during solidification[10][11][44][45][46].

As shown in Fig. 2, the dendritic morphologies in the studied alloys were found to transform from a six-fold snowflake-like structure in $\mathrm{Mg}-25 \mathrm{wt} . \% \mathrm{Zn}$ to a hyperbranched structure in Mg-38wt.\%Zn and then subsequently back to a six-fold symmetry morphology in Mg-50wt.\%Zn alloy. In Mg-25wt.\%Zn a typical six-fold structure was present from the view of the basal plane. However, the dendritic arms were found to split on the basal plane and tended to grow along the direction of the prismatic plane. In contrast, while a six-fold structure was also observed in $\mathrm{Mg}-50 \mathrm{wt} . \% \mathrm{Zn}$ from the 
perspective of basal plane, only 4 branches were present on the prismatic plane, and the branch arms on the basal plane disappeared and grew along a direction between the basal plane and prismatic plane[11].

In order to further confirm the dendrite orientation transition, XRD and EBSD measurements were performed on the quenched samples. From the XRD patterns shown in Fig. 4, three different phase constituents, $\alpha-\operatorname{Mg}(P 63 / m m c, a=b=3.209 \dot{A}$, $\left.\mathrm{sc}=5.211 \dot{A}, \mathrm{c} / \mathrm{a}=1.624, \alpha=\beta=90^{\circ}, \gamma=120^{\circ}\right), \operatorname{Mg}_{7} Z_{3}\left(I, \mathrm{a}=\mathrm{b}=\mathrm{c}=14.170 \dot{\mathrm{A}}, \alpha=\beta=\gamma=90^{\circ}\right)$, $\operatorname{Mg}_{2} Z_{11}\left(\operatorname{Pm} 3(200), a=b=c=8.552 \dot{\mathrm{A}}, \alpha=\beta=\gamma=90^{\circ}\right)$ were observed and the $<11 \overline{2} 0>$ direction of $\alpha-\mathrm{Mg}$ on the basal plane can be observed in $\mathrm{Mg}-25 \mathrm{wt} . \% \mathrm{Zn}$ alloy, while in Mg- $50 \mathrm{wt} . \% \mathrm{Zn}$, it is clear that $<11 \overline{2} 0>$ disappeared and only $<11 \overline{2} 1>$ was found. In Mg$38 \mathrm{wt} . \% \mathrm{Zn}$, some anomalous diffraction peaks were observed. This is further clarified by the EBSD results, shown in Fig. 5. Specifically, the preferred growth direction of $\alpha$ Mg for Mg-25wt.\%Zn was found to be $<11 \overline{2} 0>$ (Fig. 5 a2) and in Mg-50wt.\%Zn alloy, the preferential orientation was observed to be $<11 \overline{2} 1>$ (Fig. $5 \mathrm{c} 2$ ). The results for Mg$38 \mathrm{wt} . \% \mathrm{Zn}$ (Fig. 5 b) show that the branching structure and growth orientation of these dendrites were much more complicated than in either the Mg-25wt.\%Zn and Mg50wt.\%Zn. 


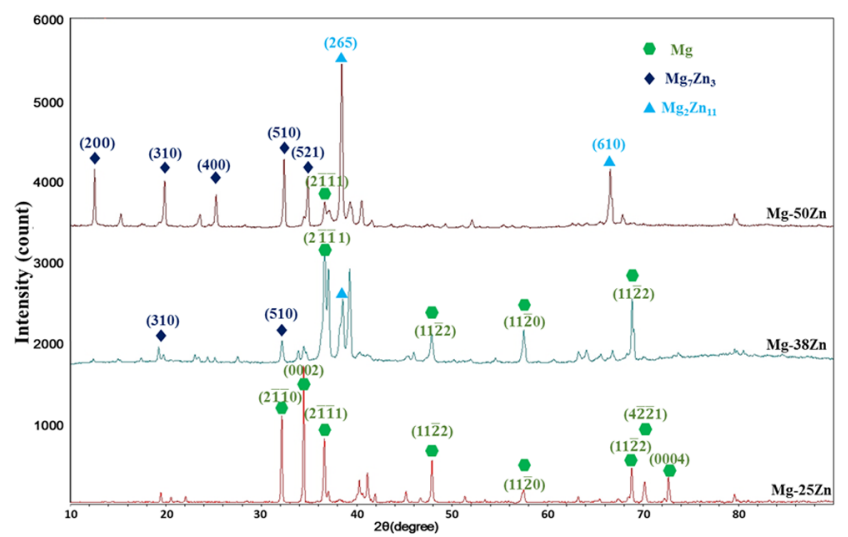

Fig. 4: XRD patterns of Mg-25/38/50wt.\%Zn alloys showing the orientation selection in these three alloys.
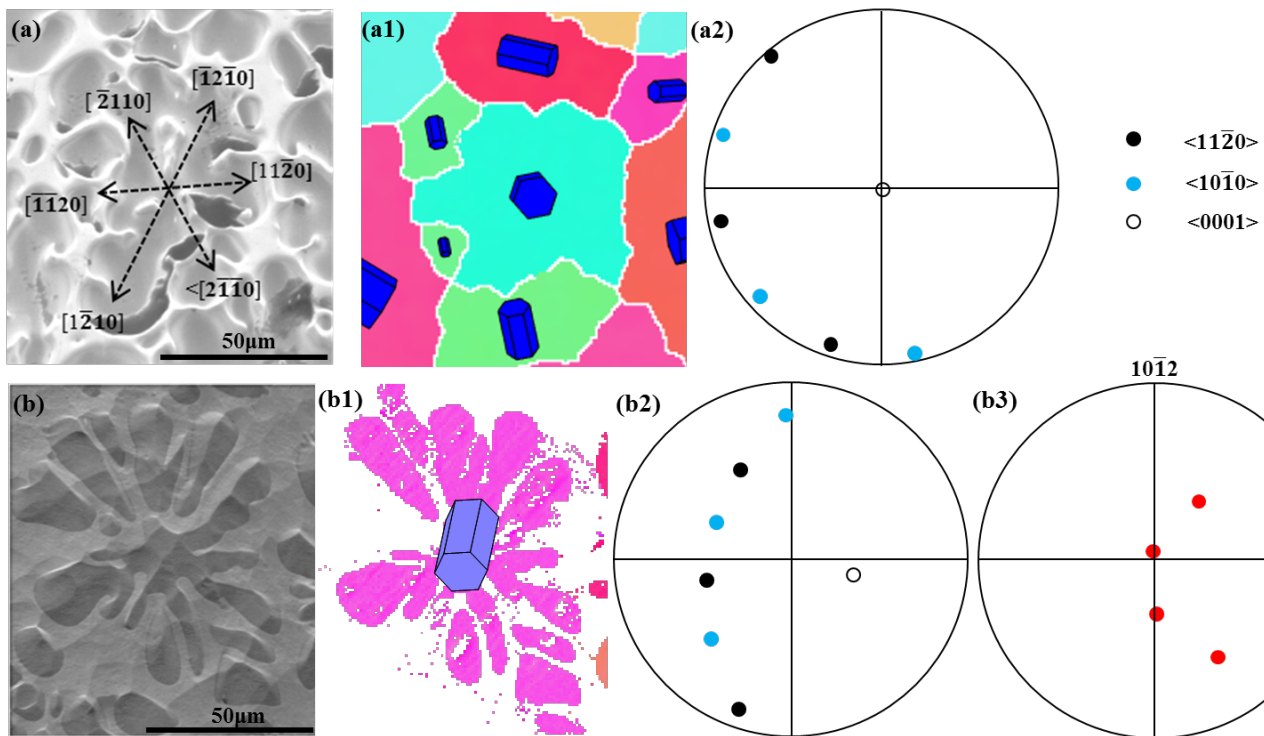

(b1)

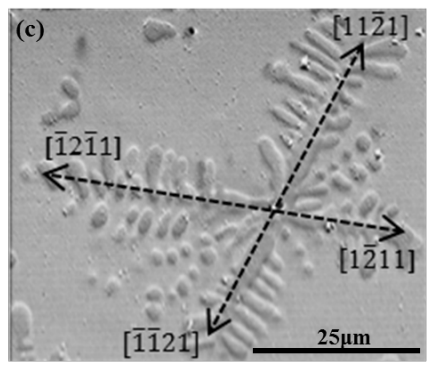

(c2)
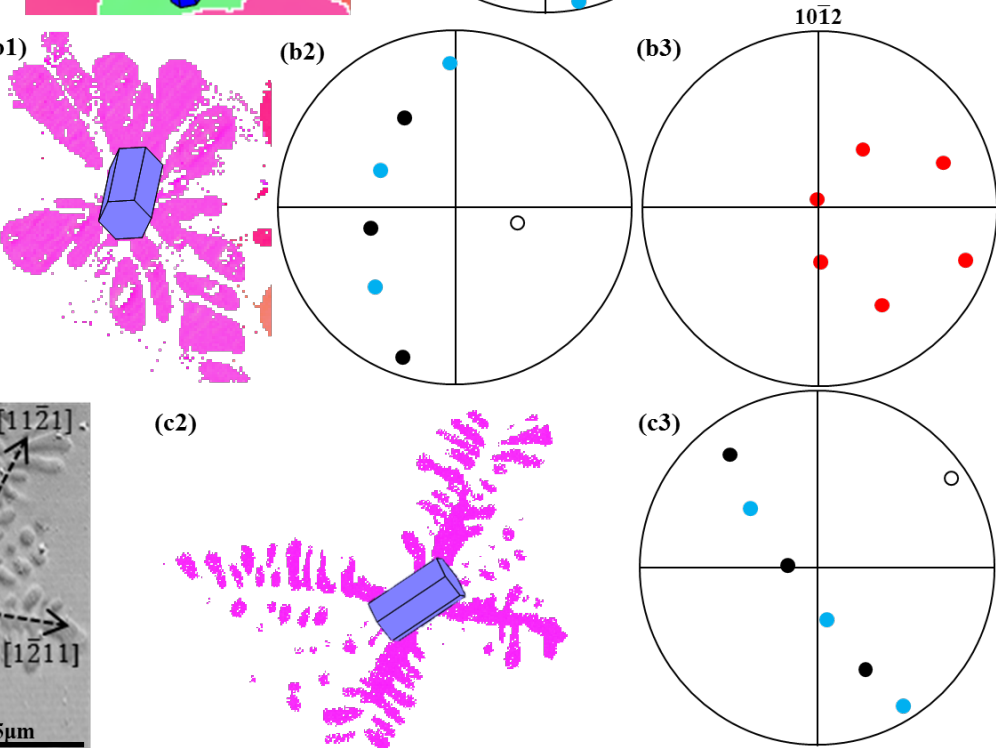

Fig. 5: EBSD measurement showing the preferential growth direction in: (a-a2) Mg25wt.\%Zn, (b-b3) Mg-38wt.\%Zn, and (c-c2) Mg-50wt.\%Zn 

by the anisotropy in interfacial free energy and thus the transition in dendrite growth orientation can be attributed to changes in this quantity [4]. There are a variety of factors that might affect the anisotropy in solid-liquid interfacial free energy during the growth of a dendrite: including (i) lattice defects (lattice distortions and/or stacking faults), (ii) the formation of twin grains, (iii) fast cooling rates, and (iv) an increase in the concentration of a solute element with high anisotropy in solid-liquid interfacial free energy.

Of these, the first can be discounted in $\mathrm{Mg}-\mathrm{Zn}$ because although lattice distortions would be expected to form. 

dendrite orientation transition is caused by the increase in solute content as $\mathrm{Zn}$ is known to have a very strong anisotropy in solid/liquid interfacial energy. Because of the low solubility of $\mathrm{Zn}$ in $\mathrm{Mg}$, we hypothesize that the structural changes occur on the liquid side, perhaps by a concentration-dependent atom cluster that forms adjacent to the dendrite growth front and changes continually the surface energy. supported by the molecular dynamics (MD) simulations of Sun et al.[45]. In these simulations, it was found that the anisotropy between different symmetric directions in pure magnesium was rather small, therefore, the interface free energy anisotropy of $\alpha$ Mg could be easily changed through the addition of a solute with high anisotropy. Due to present limitaions of MD calculations in binary systems[47], the community cannot yet perform realistic simulations for the interfacial free energy anistropy in $\mathrm{Mg}-\mathrm{Zn}$ observed in this work. numerical simulations, i.e. phase-field models, that are currently being used for predicting dendrite growth patterns in engineering metals. However, the phase-field simulation results will only match experimental results if the anisotropy function is properly accounted for. To give an example, although the $\mathrm{Mg}-\mathrm{Zn}$ phase field 
simulations of Wang et al. [10] did show hyper-branched dendrite morphology at intermediate compositions, they used an anisotropy function having the preferred orientations of $<1120>$ and $<2245>$ based on [48]. These simulation results do not agree very well with the experimental results in this study where the dendrite orientation transitioned from $<1120>$ to $<1121>$. Thus, in hep systems, it is clear that a combination of simulations and experiments is needed to accurately quantify anisotropy in interfacial free energy.

\subsubsection{D evolution of hyper-branched structures in Mg-Zn alloy}

Through analysis of the 3D datasets, it appears that three tip-splitting mechanisms are responsible for the formation of hyper-branched structures at Mg-38wt.\%Zn. These are shown in Fig. 6: doublon (Fig. 6 a1-a4 and d1-d4), triplon (Fig. 6 b1-b4) and quadruplon (Fig. 6 c1-c4), respectively. These hyper-branched structures are similar to ones displayed in succinonitrile-camphor under microgravity condition (Fig. 6 a1, b1, c1) by Bergeon et al.[49]. However, only the final shapes (doublon, triplon or quadruplon) were obtained in that study due to the limited temporal resolution of the experiment; the evolution of seaweed structure and the tip splitting mechanisms were not captured. In the present study, the mechanisms of tip splitting were directly captured. Specifically, (i) for the doubloon, the dendrite tip was observed to split in two parts about its central axis with a narrow liquid groove in between (Fig. 6 a2-a4) and it is similar to what was observed in directionally solidified $\mathrm{Al}-4 \mathrm{wt} . \% \mathrm{Cu}[50]$ and pure $\mathrm{Cu}[51]$ metals in previous studies; (ii) for the triplon, the dendrite tip was observed to split into three small tips simultaneously during growth (Fig. 6 b2-b4); (iii) for the 
(a2)

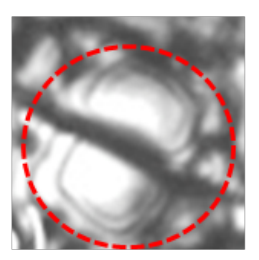

(b1)

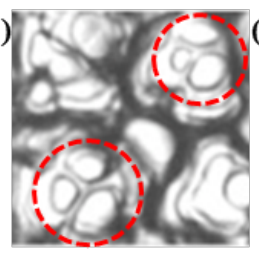

(c1)

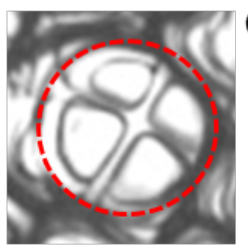

(d1)

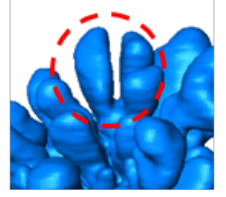

$\Delta T=19.8^{\circ} \mathrm{C}$

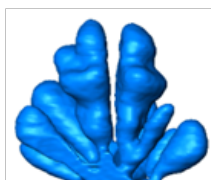

$\Delta T=18.0^{\circ} \mathrm{C}$

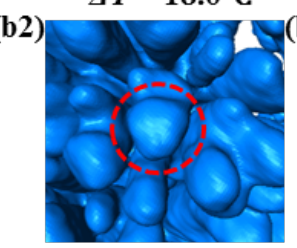

$\Delta T=12.6^{\circ} \mathrm{C}$

(c2)

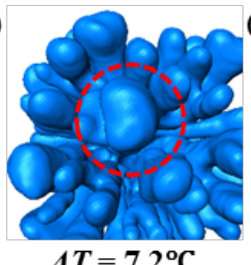

(d2)

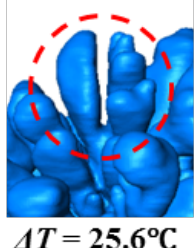

(a3)

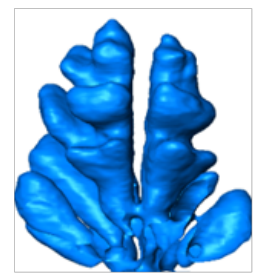

$\Delta T=42.4^{\circ} \mathrm{C}$

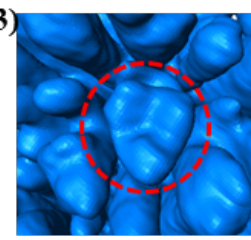

$\Delta T=16.2^{\circ} \mathrm{C}$

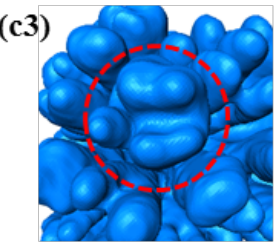

$\Delta T=10.8^{\circ} \mathrm{C}$

(d3)

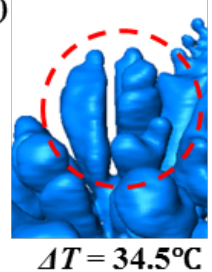

(a4)
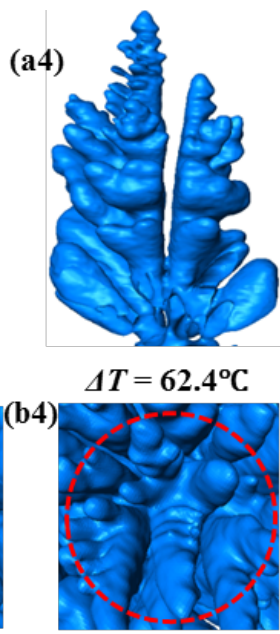

$\Delta T=19.8^{\circ} \mathrm{C}$

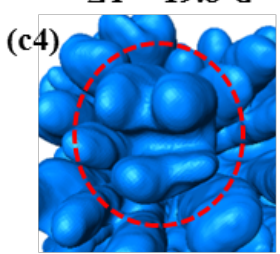

$\Delta T=14.4^{\circ} \mathrm{C}$

(d4)

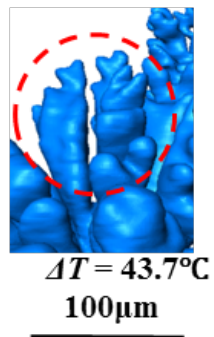

Fig. 6: Dendrite tip splitting mechanisms during the solidification of (a1, b1, c1) bulk transparent (succinonitrile-camphor) alloy ( after ref.[9]), (a2-a4, b2-b4, c2-c4) Mg$38 \mathrm{wt} . \%$ alloy and (d1-d4) Mg-50wt.\%. ( $\boldsymbol{\Delta T}$ indicates the temperature below liquidus. Figures (a2-a4, b2-b4, c2-c4, d1-d4) share the same scale bar. Note no scale bar was given in reference[9] after which images $\mathrm{a} 1, \mathrm{~b} 1$ and $\mathrm{c} 1$ were taken).

Seaweed-like microstructures usually form under various situations like isotropic 
or weakly anisotropic conditions or with increased undercooling[52][53]. In the current study, the sample was solidified under a relatively low cooling rate, and it is unlikely that the hyper-brached structures resulted from large undercooling. Instead, we hypothesize that the formation of seaweed-like hyper-branched microstructure is a result of the $\mathrm{Zn}$ addition and the corresponding modification of the interfacial free energy anisotropy of $\alpha-\mathrm{Mg}$ dendrites. This phenomenon correlates well to that observed in Al-(10 90)wt.\%Zn alloys where a dendritic orientation transition occurred with an increase in $\mathrm{Zn}$ content and a hyper-branched structure formed at interim $\mathrm{Zn}$ concentration (e.g. Al-55wt.\%Zn)[4]. Abnormal and complex dendritic growth morphologies were also previously observed in a number of transparent systems[51][54] and metallic alloys[4][45][50]; the observations of dendrite growth in Figure 4 help to explain the development of such structures.

\subsection{Quantitative analysis}

\subsubsection{Evolution of dendrite solid fraction with temperature}

The overall evolution in volume fraction of primary $\alpha-\mathrm{Mg}$ dendrites with temperature was calculated from the 3D datasets, and is shown in Fig. 7 along with the corresponding lever rule and Scheil predictions. For the Scheil equation, the partition coefficient was assumed to be constant with a value of $k_{0}=0.146[55]$. As can be seen, the measured results for all three alloy systems, except during the later stages, were generally in agreement with the Lever rule and far from the Scheil model. In the case of $\mathrm{Mg}-50 \mathrm{wt} . \% \mathrm{Zn}$, the the rapid increase in solid fraction at $\sim 360^{\circ} \mathrm{C}$ is a result of eutectic solidification and thus the Lever rule no longer applies. Although it is widely 
recognized that the partition coefficient varies with solutal concentration in a binary system, varying $k_{0}$ for the three alloys did not provide any meaningful difference in the position of the Scheil model fraction solid relative to the experimentally-collected data. Interestingly, in the previous work for $\mathrm{Mg}-15 \mathrm{wt} . \% \mathrm{Sn}$ alloys under the similar cooling rate[35], the measured evolution in solid fraction matched the Scheil predictions and not the Lever rule. The difference in the solid fraction evolution with temperature between $\mathrm{Mg}-\mathrm{Zn}$ and $\mathrm{Mg}-\mathrm{Sn}$ alloys may result from the underlying thermodynamic parameters of the alloying elements (solute diffusion and solute partition coefficient) as either analytic curve can be shifted to fit the experimental data depending on these values. Note that the dendrite morphology will also influence the distribution of solute concentration during solidification and hence influence the evolution of solid fraction.

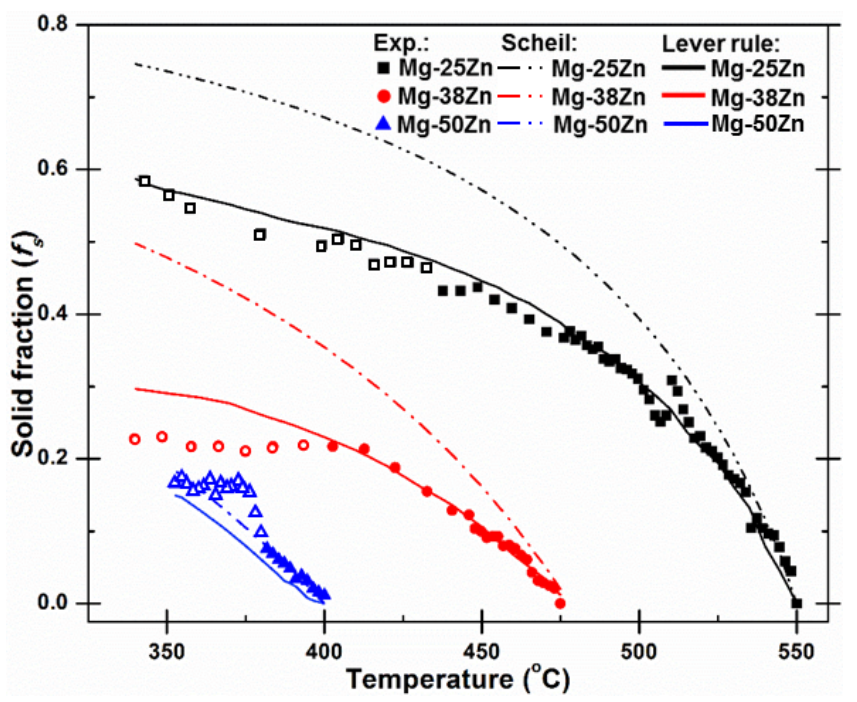

Fig. 7: Measured evolution of solid fraction together with values determined via the lever rule and Scheil Equation. (Note, change from filled to hollow symbols denotesan increase in the cooling rate near the end of experiment.) 


\subsubsection{Influence of zinc on dendrite tip velocity in the mushy zone during} solidification

The evolution in dendrite tip velocity $\left(V_{\text {tip }}\right)$ in the mushy zone was characterized in each of the three alloys in order to provide insight into the effect of solute concentration on dendrite growth kinetics. This was carried out by segmenting several representative equiaxed dendrites and then measuring the evolving dendrite arm length $(L)$ during the solidification process. As can be seen in Fig. 8, $V_{\text {tip }}$ in the mushy zone was observed in all three alloys to decrease continuously with time and then arrest at the end of solidification. The gradual decrease of dendrite tip growth rate was mainly ascribed to the rejection of solute ahead of the growing grains, hindering the growth of dendrite arms. As demonstrated in an Al-Cu alloy by Bogno et al.[24] (Fig. 4a and b) the decelerating regime emerges when the far-field solute concentration ahead of the dendrite tip starts to increase because of an overlap between the solute fields of adjacent grains. It must be stated that the initial accelerating growth stage of dendrites are not captured due to a limited temporal resolution between tomograms; this phenomenon can only be captured using ultrafast $2 \mathrm{D}$ radiography which which will be on the order of 1000 times faster than tomography[56].

Fig. 8 also shows that all three curves reach a plateau at about 220 s after the initial solidification. The duration of the decelerating growth stage as a fraction of total solidification time for each of the Mg-25/38/50wt.\%Zn alloys is estimated to be about $5 \%, 11 \%$ and $20 \%$, respectively. This indicates that the dendrite morphology evolution was dominated by tip growth only at the early stage of solidification and then 
solidification occurred through lengthening and thickening of secondary arms.

As plotted in Fig. 8, the fraction of the dendrite tip growth period with respect to the total solidification time increases continuously with increasing $\mathrm{Zn}$ content. The experimental results therefore indicate that the amount of $\mathrm{Zn}$ influences dendritic growth kinetics during solidification. This effect can be considered in terms of growth restriction factor (GRF)[57]. Specifically, the addition of solute elements generates constitutional undercooling within a diffusion layer ahead of the solid/liquid interface, restricting dendritic growth and thus limiting the overall growth rate. As suggested by Lipton et al.[40], the dendrite tip growth velocity in the mushy zone was closely related to solute concentration and dendrite morphology (tip radius). The tip radius in $\mathrm{Mg}-\mathrm{Zn}$ alloys was demonstrated to decrease with the increasing zinc concentration, as shown in Fig. 3. The difference of dendrite tip velocity in the mushy zone might also be attributed to the diversity of dendrite morphologies and growth orientations.

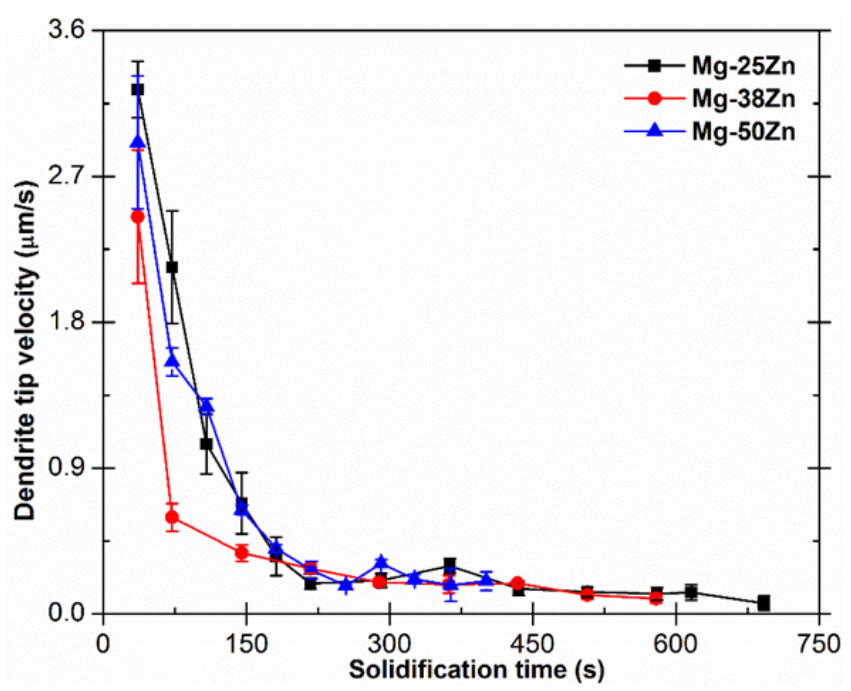

Fig. 8 Average dendrite tip velocity in the mushy zone as a function of solidification time for Mg-25/38/50wt.\%Zn alloys. A few dendrites were measured for each composition. The error bars in the figure indicate the standard deviation of the measured values. 
393

394

395

396

397

398

399

400

401

402

403

404

405

406

407

408

409

410

411

412

413

414

\subsubsection{Effect of solute concentration on specific surface area evolution}

The microstructure evolution during dendritic growth and coarsening can be assessed through analysis of the change in specific surface area $\left(S_{v}\right)$ with solidification time or solid volume fraction. Voorhees et al.[13] reported that the inverse of specific surface area usually follows a $S_{v}{ }^{-1} \sim t^{1 / 3}$ power law during isothermal coarsening of both equiaxed and directionally solidified dendrites. Further research has shown that the temporal exponent is not exactly $1 / 3$ but varies based on solidification conditions[59].

A more general law is thus, $S_{v} / S_{v_{0}}=\left[1+k \times\left(S_{v_{0}}\right)^{n} \times \mathrm{t}\right]^{-1 / n}$

or $S_{v}{ }^{-n}-S_{v_{0}}{ }^{-n}=k t$ (Eq. 3) where $S_{v_{0}}$ is the initial value of $S_{v}(1 / \mu \mathrm{m}), t$ is the solidification time, and $n$ and $k$ are fitting parameters. $k\left(\mu \mathrm{m}^{n} / \mathrm{s}\right)$ is generally known as the coarsening rate constant. Although Equation (3) was derived for isothermal conditions with constant values of interfacial energy and diffusion coefficient, it will also provide a good fit during non-isothermal conditions if one assumes that the temperature variation in the interfacial energy and diffusion coefficient are small[60].

Researchers are working to overcome this limitation, as recently demonstrated by Beckermann et al. [61] who proposed a more general equation for specific surface evolution during solidification.

Fig. 9 shows the plots of $S_{v} / S_{v 0}$ as a function of time for the three Mg-Zn alloys, along with the fitted curves at the early growth stage. As can be seen in the figure, the specific surface area for all three alloys decreases continuously with solidification time, as expected. The specific surface area at the final stage of solidification is also seen to increase with increased $\mathrm{Zn}$ content. As the lines show, Eq. (3) provides a reasonable fit 
to the experimental data, assuming different fitting parameters are used. With increasing $\mathrm{Zn}$ concentration, the exponent $n$ increases slightly, while the coarsening rate $k$ decreases dramatically. The increasing $n$ and decreasing $k$ indicate a slower coarsening process. This is consistent with the qualitative results shown in Figure 2, where coarsening was clearly evident in the Mg-25wt.\%Zn alloy, but hardly visible in the Mg$50 \mathrm{wt} \% \mathrm{Zn}$ alloy. The results are also consistent with results of isothermal coarsening experiments conducted on this alloy system [37].

To comprehensively reveal the evolution of a specific surface area, especially in relation to growing dendrites during solidification, it is imperative to quantify the specific surface area of dendrites by temperature or solid fraction, as described in a model proposed by Cahn[62] and further developed by Rath[63]. This model links the specific surface area $\left(S_{v}\right)$ of the dendrite, to its solid fraction $\left(f_{s}\right)$ during solidification and is expressed as follows: $S_{v}=K \times\left(f_{s}\right)^{m} \times\left(1-f_{s}\right)^{n}$ where $K, m$ and $n$ are constants, $f_{s}$ is the volume fraction of solid phase and $m=n=2 / 3$ according to[62] or $0<(m, n)<1$ based on the fitting value from results described in[63]. Fig. 10 illustrates the variations of $S_{v}$ with solid fraction $\left(f_{s}\right)$, along with the fitted curves. As can be seen, the curves are able to match the experimental data although $m$ and $K$ must both be taken as fitting parameters. Interestingly, the exponent $m$ has a negative value. Cahn and Rath's model assumes the initial grain shape is globular, hence the specific surface area initially increases with solid fraction and then continually decreases when $f_{\mathrm{s}}$ exceeded $\sim 0.5$. However, in this study, as Figs. 1-3 show, the initial growing grains are already dendritic-like with hierarchical branches. 

the limitation and restriction of solute diffusion at higher solid fraction, it is reasonable that the coarsening process tends to decelerate with increasing solid fraction, causing the value of $m$ to be negative, i.e. we are not capturing the very initial stages of spherical growth and it's degeneration, which is happening on a very fine scale and/or a very short time period.

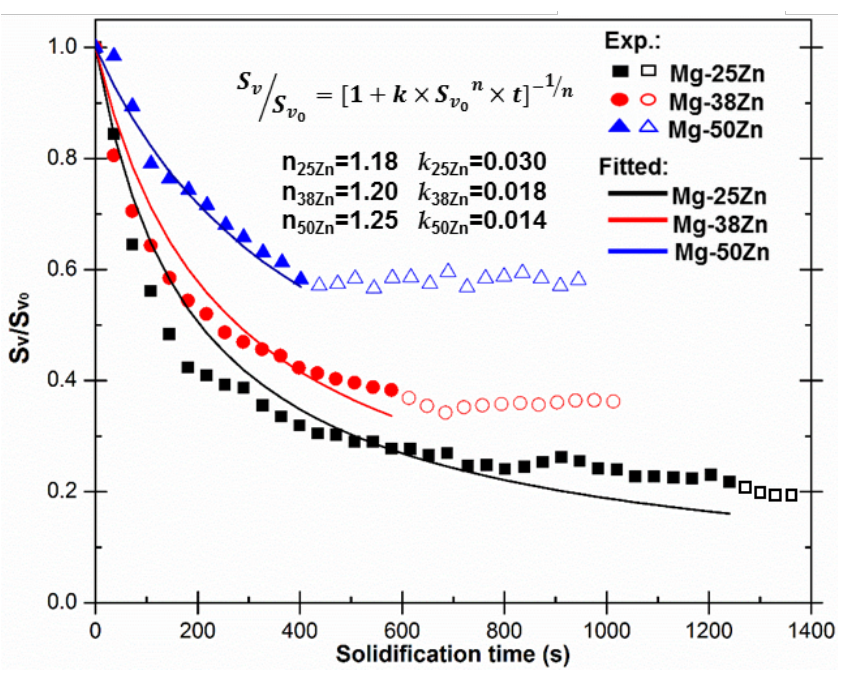

Fig. 9 Normalised specific surface area evolution as a function of solidification time in Mg-25/38/50wt.\%Zn alloys. Fitting curves using the model proposed by Poirier in ref.[59] (Eq. 2) are also plotted. (Note, change from filled to hollow symbols denotes an increased cooling rate; hollow data was not used for fitting.)

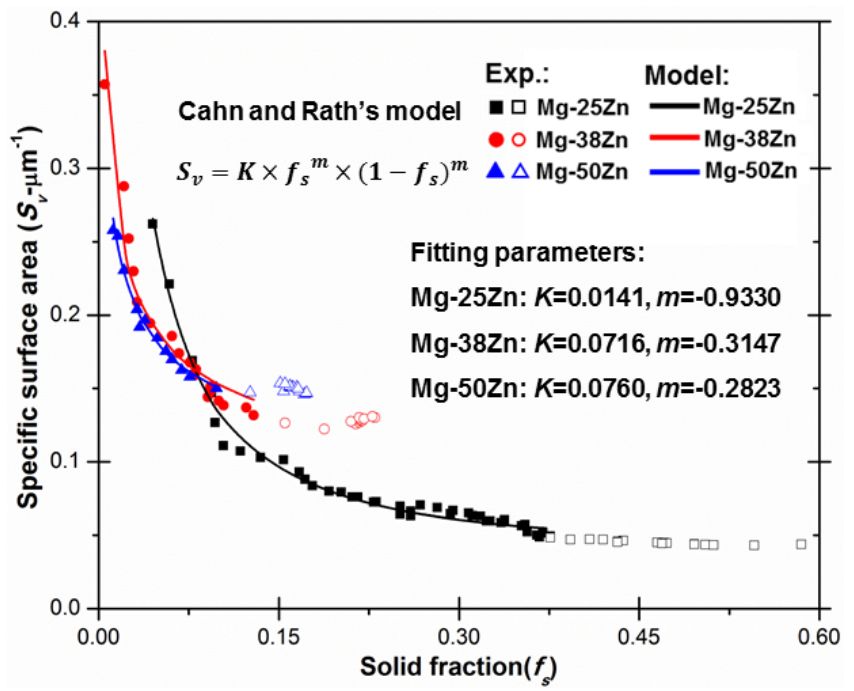

Fig. 10 Specific surface area evolution as a function of solid fraction, and fitted curves using modified Rath and Cahn's model. 


\section{Conclusions}

Using 4D synchrotron X-ray tomography, the dendritic growth dynamics of primary $\alpha-\mathrm{Mg}$ grains during the solidification of $\mathrm{Mg}-\mathrm{Zn}$ alloys with various $\mathrm{Zn}$ concentrations was investigated both qualitatively and quantitatively. These in situ observations demonstrate conclusively that a dendritic morphology transition occurs in $\mathrm{Mg}-\mathrm{Zn}$ alloys. This finding, along with prior similar findings in fcc Al, strongly supports the hypothesis that $\mathrm{Zn}$ modifies the anisotropy in interfacial energy in alloy systems that have inherenly weak anisotropy in interfacial energy (e.g. Mg, Al).

Synchrotron tomography revealed the mechanisms by which hyper-branched structures form, i.e. via doublon, triplon and quardrulon (or doubling doublons). The dynamic formation of these structures was captured and quantified, revealing new tipsplitting mechanisms.

Analysis of the time resolved 3D images allowed the first quantification of the microstructural evolution of $\mathrm{Mg}-\mathrm{Zn}$ alloys during solidification, including: solid fraction $\left(f_{s}\right)$, dendrite tip growth velocity $\left(V_{t i p}\right)$, and specific surface area $\left(S_{v}\right)$. The $f_{s}$ variations with temperature were found to correlate well with lever rule. Dendrite tip growth was found to decelerate continuously with solidification time, and dendrite tip growth as a mechanism of dendrite morphology evolution was found to dominate only at a very early stage of solidification. The evolution of $S_{v}$ during dendritic growth compared well with Poirer's model[59], demonstrating the rate of dendritic coarsening decreases with increasing Zn concentration. The data was also fit to Cahn and Rath's equation to reveal the evolution of $S_{v}$ with $f_{s}$ during solidification. 

dynamics during the solidification of these magnesium alloys, providing a method for

475 both informing and validating numerical models of microstructural evolution, e.g.

476 phase field simulations and cellular automata methods.

\section{Acknowledgements}

478 The work was financially supported by the EPSRC (EP/I02249X/1, EP/K007734/1, and 479 EP/M009688/1) and National Natural Science Foundation of China (Grants 51690162 480 and 51701112). S.S. acknowledges the support from China Postdoctoral Science 481 Foundation (Nos. 2017T100291 and 2017M611530). We acknowledge Diamond Light 482 Source for providing the beamtime (MT11837-1), staff at I13 beamline for technical 483 assistance and group members (especially Drs. W. Xu, M. D Callaghan, G. Zeng, and 484 W. Mirihanage) for help during beamline experiments. We also acknowledge the use of 485 facilities and support provided by the Research Complex at Harwell.

\section{Data statement}

Representative samples of the research data are given in the figures and supplementary data. Other datasets generated and/or analysed during this study are not publicly available due to their large size but are available from the corresponding authors on reasonable request. 


\section{References}

[1] T.M. Pollock, Weight loss with magnesium alloys, Science. 328 (2010) 986-987.

[2] B. Mordike, T. Ebert, Magnesium, Mater. Sci. Eng. A. 302 (2001) 37-45.

[3] W. Xu, N. Birbilis, G. Sha, Y. Wang, J.E. Daniels, Y. Xiao, M. Ferry, A high-specific-strength and corrosion-resistant magnesium alloy, Nat. Mater. 14 (2015) 1229-1235.

[4] T. Haxhimali, A. Karma, F. Gonzales, M. Rappaz, Orientation selection in dendritic evolution., Nat. Mater. 5 (2006) 660-664

[5] J.A. Dantzig, M. Rappaz, Solidification, EPFL press, 2009.

[6] M.E. Glicksman, Principles of solidification: an introduction to modern casting and crystal growth concepts, Springer Science \& Business Media, 2010.

[7] K. Fisher, W. Kurz, Fundamentals of solidification, Trans Tech Publ. (1986).

[8] E. Ben-Jacob, P. Garik, The formation of patterns in non-equilibrium growth, Nature. 343 (1990) 523-530.

[9] H. Nguyen-Thi, In situ observation of solidification patterns in diffusive conditions, Acta Mater. 108 (2016).

[10] M. Wang, Y. Xu, Q. Zheng, S. Wu, T. Jing, N. Chawla, Dendritic growth in Mg-based alloys: Phasefield simulations and experimental verification by X-ray synchrotron tomography, Metall. Mater. Trans. A Phys. Metall. Mater. Sci. 45 (2014) 2562-2574.

[11] S. Shuai, E. Guo, Q. Zheng, M. Wang, T. Jing, Y. Fu, Three-dimensional $\alpha$-Mg dendritic morphology and branching structure transition in Mg-Zn alloys, Mater. Charact. 118 (2016) 304-308.

[12] J. Alkemper, P.W. Voorhees, Quantitative serial sectioning analysis, J. Microsc. 201 (2001) 388394.

[13] D. Kammer, P.W. Voorhees, The morphological evolution of dendritic microstructures during coarsening, Acta Mater. 54 (2006) 1549-1558.

[14] E. Maire, P.J. Withers, Quantitative X-ray tomography, Int. Mater. Rev. 59 (2014) 1-43.

[15] M. Yang, S.M. Xiong, Z. Guo, Effect of different solute additions on dendrite morphology and orientation selection in cast binary magnesium alloys, Acta Mater. 112 (2016) 261-272.

[16] F. Li, J. Zhang, Q. Dong, Y. Dai, Y. Fu, H. Xie, J. Mi, F. Yin, B. Sun, In situ synchrotron X-ray studies of the coupled effects of thermal and solutal supercoolings on the instability of dendrite growth, Mater. Charact. 109 (2015) 9-18.

[17] S. Terzi, E. Boller, L. Salvo, M. Suéry, In situ X-ray microtomography study of the solidification and remelted microstructures of Al-Cu alloys, Int. J. Cast Met. Res. 22 (2009) 275-278.

[18] C. Puncreobutr, A. B. Phillion, J.L. Fife, P. Rockett, A. P. Horsfield, P.D. Lee, In situ quantification of the nucleation and growth of Fe-rich intermetallics during Al alloy solidification, Acta Mater. 79 (2014) 292-303.

[19] Y. Wang, L. Peng, Y. Ji, X. Cheng, N. Wang, Y. Zhao, Y. Fu, L.Q. Chen, W. Ding, The effect of low cooling rates on dendrite morphology during directional solidification in Mg-Gd alloys: In situ Xray radiographic observation, Mater. Lett. 163 (2016) 218-221.

[20] A.B. Phillion, R.W. Hamilton, D. Fuloria, A.C.L. Leung, P. Rockett, T. Connolley, P.D. Lee, In situ X-ray observation of semi-solid deformation and failure in Al-Cu alloys, Acta Mater. 59 (2011) 14361444.

[21] C.L. Mendis, D. Tolnai, A. Stark, N. Schell, K.U. Kainer, N. Hort, In Situ Investigation of Microstructure Evolution during Solidification of $\operatorname{Mg} 10 \mathrm{CaxGd}(\mathrm{x}=5,10,20)$ Alloys, Acta Phys. Pol. 
A. 128 (2015) 606-611.

[22] K.M. Kareh, P.D. Lee, R.C. Atwood, T. Connolley, C.M. Gourlay, Revealing the micromechanisms behind semi-solid metal deformation with time-resolved X-ray tomography, Nat Commun. 5 (2014) 4464.

[23] S. Karagadde, P.D. Lee, B. Cai, J.L. Fife, M.A. Azeem, K.M. Kareh, C. Puncreobutr, D. Tsivoulas, T. Connolley, R.C. Atwood, Transgranular liquation cracking of grains in the semi-solid state, Nat. Commun. 6 (2015) 8300.

[24] A. Bogno, H. Nguyen-Thi, G. Reinhart, B. Billia, J. Baruchel, Growth and interaction of dendritic equiaxed grains: In situ characterization by synchrotron X-ray radiography, Acta Mater. 61 (2013) 1303-1315.

[25] P.D. Lee, J.D. Hunt, Hydrogen porosity in directional solidified aluminium-copper alloys:in situ observation, Acta Mater. 45 (1997) 4155-4169.

[26] R.H. Mathiesen, L. Arnberg, X-ray radiography observations of columnar dendritic growth and constitutional undercooling in an Al-30wt\%Cu alloy, Acta Mater. 53 (2005) 947-956.

[27] G. Reinhart, N. Mangelinck-Noël, H. Nguyen-Thi, T. Schenk, J. Gastaldi, B. Billia, P. Pino, J. Härtwig, J. Baruchel, Investigation of columnar-equiaxed transition and equiaxed growth of aluminium based alloys by X-ray radiography, Mater. Sci. Eng. A. 413-414 (2005) 384-388.

[28] K. Nogita, H. Yasuda, A. Prasad, S.D. McDonald, T. Nagira, N. Nakatsuka, K. Uesugi, D.H. Stjohn, Real time synchrotron X-ray observations of solidification in hypoeutectic Al-Si alloys, Mater. Charact. 85 (2013) 134-140.

[29] A. Prasad, S.D. McDonald, H. Yasuda, K. Nogita, D.H. StJohn, A real-time synchrotron X-ray study of primary phase nucleation and formation in hypoeutectic Al-Si alloys, J. Cryst. Growth. 430 (2015) 122-137.

[30] G. Reinhart, A. Buffet, H. Nguyen-Thi, B. Billia, H. Jung, N. Mangelinck-Noël, N. Bergeon, T. Schenk, J. Härtwig, J. Baruchel, In-situ and real-time analysis of the formation of strains and microstructure defects during solidification of Al-3.5Ni alloys, Metall. Mater. Trans. A Phys. Metall. Mater. Sci. 39 A (2008) 865-874.

[31] D. Tolnai, P. Townsend, G. Requena, L. Salvo, J. Lendvai, H.P. Degischer, In situ synchrotron tomographic investigation of the solidification of an AlMg4.7Si8 alloy, Acta Mater. 60 (2012) 25682577.

[32] S. Terzi, J.A. Taylor, Y.H. Cho, L. Salvo, M. Suéry, E. Boller, A.K. Dahle, In situ study of nucleation and growth of the irregular $\alpha-\mathrm{Al} / \beta-\mathrm{Al} 5 \mathrm{FeSi}$ eutectic by $3-\mathrm{D}$ synchrotron X-ray microtomography, Acta Mater. 58 (2010) 5370-5380.

[33] N. Limodin, L. Salvo, E. Boller, M. Suéry, M. Felberbaum, S. Gailliègue, K. Madi, In situ and realtime 3-D microtomography investigation of dendritic solidification in an Al-10wt.\% Cu alloy, Acta Mater. 57 (2009) 2300-2310.

[34] B. Cai, J. Wang, A. Kao, K. Pericleous, A.B. Phillion, R.C. Atwood, P.D. Lee, 4D synchrotron Xray tomographic quantification of the transition from cellular to dendrite growth during directional solidification, Acta Mater. 117 (2016) 160-169.

[35] S. Shuai, E. Guo, A.B. Phillion, M.D. Callaghan, T. Jing, P.D. Lee, Fast synchrotron X-ray tomographic quantification of dendrite evolution during the solidification of [Formula presented] alloys, Acta Mater. 118 (2016) 260-269.

[36] D. Casari, W.U. Mirihanage, K. V. Falch, I.G. Ringdalen, J. Friis, R. Schmid-Fetzer, D. Zhao, Y. Li, W.H. Sillekens, R.H. Mathiesen, $\alpha-\mathrm{Mg}$ primary phase formation and dendritic morphology transition 
in solidification of a Mg-Nd-Gd-Zn-Zr casting alloy, Acta Mater. 116 (2016) 177-187.

[37] E. Guo, A.B. Phillion, B. Cai, S. Shuai, D. Kazantsev, T. Jing, P.D. Lee, Dendritic evolution during coarsening of Mg-Zn alloys via 4D synchrotron tomography, Acta Mater. 123 (2017) 373-382.

[38] W. Xu, A.P. Horsfield, D. Wearing, P.D. Lee, First-principles calculation of $\mathrm{Mg} / \mathrm{MgO}$ interfacial free energies, J. Alloys Compd. 650 (2015) 228-238.

[39] H. Men, B. Jiang, Z. Fan, Mechanisms of grain refinement by intensive shearing of AZ91 alloy melt, Acta Materialia. 58 (2010) 6526-6534.

[40] J. Lipton, M.E. Glicksman, W. Kurz, Dendritic growth into undercooled alloy metals, Mater. Sci. Eng. 65 (1984) 57-63.

[41] M.Y. Wang, J.J. Williams, L. Jiang, F. De Carlo, T. Jing, N. Chawla, Dendritic morphology of $\alpha-$ $\mathrm{Mg}$ during the solidification of Mg-based alloys: 3D experimental characterization by X-ray synchrotron tomography and phase-field simulations, Scr. Mater. 65 (2011) 855-858.

[42] M. Wang, T. Jing, B. Liu, Phase-field simulations of dendrite morphologies and selected evolution of primary $\alpha-\mathrm{Mg}$ phases during the solidification of Mg-rich Mg-Al-based alloys, Scr. Mater. 61 (2009) 777-780.

[43] K. Pettersen, O. Lohne, N. Ryum, Dendritic solidification of magnesium alloy AZ91, Metall. Trans. A. 21 (1990) 221-230.

[44] S. Shuai, E. Guo, Q. Zheng, M. Wang, T. Jing, Characterisation of three-dimensional dendritic morphology and orientation selection of $\alpha-\mathrm{Mg}$ in $\mathrm{Mg}-\mathrm{Ca}$ alloy using synchrotron X-ray tomography, Mater. Charact. 111 (2016) 170-176.

[45] S. Shuai, E. Guo, M. Wang, M.D. Callaghan, T. Jing, Q. Zheng, P.D. Lee, Anomalous $\alpha-M g$ Dendrite Growth During Directional Solidification of a Mg-Zn Alloy, Metall. Mater. Trans. A Phys. Metall. Mater. Sci. 47 (2016) 4368-4373.

[46] D.Y. Sun, M.I. Mendelev, C. A. Becker, K. Kudin, T. Haxhimali, M. Asta, J.J. Hoyt, a. Karma, D.J. Srolovitz, Crystal-melt interfacial free energies in hcp metals: A molecular dynamics study of Mg, Phys. Rev. B - Condens. Matter Mater. Phys. 73 (2006) 1-12.

[47] S. Angioletti-Uberti, M. Ceriotti, P.D. Lee, M.W. Finnis, Solid-liquid interface free energy through metadynamics simulations, Phys. Rev. B - Condens. Matter Mater. Phys. 81 (2010) 1-12.

[48] M.Y. Wang, Y.J. Xu, T. Jing, G.Y. Peng, Y.N. Fu, N. Chawla, Growth orientations and morphologies of $\alpha$-Mg dendrites in Mg-Zn alloys, Scr. Mater. 67 (2012) 629-632.

[49] N. Bergeon, A. Ramirez, L. Chen, B. Billia, J. Gu, R. Trivedi, Dynamics of interface pattern formation in 3D alloy solidification: First results from experiments in the DECLIC directional solidification insert on the International Space Station, J. Mater. Sci. 46 (2011) 6191-6202.

[50] Y. Chen, B. Billia, D.Z. Li, H. Nguyen-Thi, N.M. Xiao, A.A. Bogno, Tip-splitting instability and transition to seaweed growth during alloy solidification in anisotropically preferred growth direction, Acta Mater. 66 (2014) 219-231.

[51] A. M. Mullis, K.I. Dragnevski, R.F. Cochrane, The transition from the dendritic to the seaweed growth morphology during the solidification of deeply undercooled metallic melts, Mater. Sci. Eng. A. 375-377 (2004) 157-162.

[52] B. Utter, E. Bodenschatz, Double dendrite growth in solidification, Phys. Rev. E - Stat. Nonlinear, Soft Matter Phys. 72 (2005) 1-6.

[53] E. Brener, D. Temkin, T. Abel, Morphology diagram of possible structures in di usional growth, 249 (1998) 73-81.

[54] N. Provatas, Q. Wang, M. Haataja, M. Grant, Seaweed to dendrite transition in directional 
solidification., Phys. Rev. Lett. 91 (2003) 155502.

[55] N.C. Verissimo, C. Brito, W.L.R. Santos, N. Cheung, J.E. Spinelli, A. Garcia, Interconnection of Zn content, macrosegregation, dendritic growth, nature of intermetallics and hardness in directionally solidified Mg-Zn alloys, J. Alloys Compd. 662 (2016) 1-10.

[56] Leung, CLA, Marussi, S, Atwood, RC, Towrie, M, Withers, PJ, Lee, PD, "In situ X-ray imaging of defect and molten pool dynamics in laser additive manufacturing”, Nature Comm. 9 (2018) 1355.

[57] Y.C. Lee, A. K. Dahle, D.H. StJohn, The role of solute in grain refinement of magnesium, Metall. Mater. Trans. A. 31 (2000) 2895-2906.

[58] C. Wagner. Zeitschrift Fur Elektrochemie, Berichte Der Bunsengesellschaft Fur Phys. Chemie. 65 (1961) 581-591.

[59] D.R. Poirier, S. Ganesan, M. Andrews, P. Ocansey, Isothermal coarsening of dendritic equiaxial grains in Al-15.6 wt.\% Cu alloy, Mater. Sci. Eng. A. 148 (1991) 289-297.

[60] L. Ratke, C. Beckermann, Concurrent growth and coarsening of spheres, Acta Mater. 49 (2001) 4041-4054.

[61] H. Neumann-Heyme, K. Eckert, C. Beckermann, General evolution equation for the specific interface area of dendrites during alloy solidification, Acta Mater. 140 (2017) 87-96.

[62] J.W. Cahn, Significance of average mean curvature and its determination by quantitative metallography, Trans. Metall. Soc. AIME. 239 (1967) 610.

[63] B.B. Rath, H.I. Aaronson, D.E. Laughlin, R.F. Sekerka, C.M. Wayman, Solid-Solid Phase Transformations, TMS-AIME, Warrendale, PA. (1982) 1097-1103. 